\title{
Occurrence of fungal diseases and their impact on the quality and amount of wheat grain yield in north-eastern Poland
}

\section{Występowanie chorób grzybowych i ich wpływ na wysokość plonu pszenicy w Polsce północno-wschodniej}

\author{
Paweł Wyrzykowski, Krystyna Snarska, Rafał Konecki
}

\begin{abstract}
Summary
The aim of the study was to determine the influence of fungal diseases on the quality and yields of winter wheat in north-eastern Poland. The experiment was established in winter wheat using randomized blocks with four replications, on the individual farmer's field in Dobrzyniewo Duże in Podlaskie. The chemical treatments were performed using a field knapsack sprayer, with liquid flow rate of $300 \mathrm{l} / \mathrm{ha}$. The following protection treatments were included: herbicide at the $\mathrm{BBCH} 21-23$ phase of wheat, fungicide at two phases $\mathrm{BBCH}$ 22-23 and $\mathrm{BBCH}$ 71-75. In the experiment the occurrence of sharp eyespot Rhizoctonia cerealis, septoria glume bloth Stagonospora nodorum, tan spot Drechslera tritici-repentis and leaf rust Puccinia recondita. It was found a different level of plant infection depending on the experimental variant and the applied chemical protection. The degree of infection of wheat plants significantly affected the amount of harvested yield and weight of a thousand grains. The use of fungicide and herbicide effectively reduced the occurrence of diseases.
\end{abstract}

Key words: winter wheat, fungal diseases, fungicides, yield, wheat, herbicides

\section{Streszczenie}

Celem badań było określenie wpływu chorób grzybowych na jakość i wysokość plonu pszenicy ozimej w Polsce północnowschodniej. Doświadczenie założono w pszenicy ozimej metodą bloków losowanych, w czterech powtórzeniach, na polu rolnika indywidualnego w Dobrzyniewie Dużym, w województwie podlaskim. Zabiegi chemiczne wykonano przy użyciu poletkowego opryskiwacza plecakowego, przy wydatku cieczy $300 \mathrm{l} / \mathrm{ha}$. Wykonano zabiegi: herbicydem w fazie BBCH 21-23, fungicydem w fazach BBCH 22-23 oraz BBCH 71-75. W doświadczeniu zaobserwowano występowanie: ostrej plamistości oczkowej Rhizoctonia cerealias, septoriozy plew pszenicy Stagonospora nodorum, brunatnej plamistości liści Drechslera tritici-repentis i rdzy brunatnej Puccinia recondita. Stwierdzono zróżnicowanie stopnia porażenia roślin na poszczególnych kombinacjach w doświadczeniu adekwatnie do zastosowanej ochrony chemicznej. Stopień porażenia roślin pszenicy miał ujemny wpływ na ilość zebranego plonu i masę tysiąca ziaren. Zastosowanie fungicydu oraz herbicydu najskuteczniej ograniczyło występowanie chorób.

Słowa kluczowe: pszenica ozima, choroby grzybowe, fungicydy, plon, pszenica, herbicydy 


\section{Wstęp / Introduction}

Specyficzne warunki klimatyczno-glebowe północnowschodniej Polski takie, jak: krótki okres wegetacji, mroźne zimy $\mathrm{z}$ dużymi opadami śniegu, suche lata oraz znaczny procent gleb lekkich i zakwaszonych, w wysokim stopniu ograniczają możliwość uprawy wielu gatunków roślin. Według danych statystycznych GUS, w latach 2004-2011 zboża w rejonie północno-wschodniej Polski zajmowały około 76\% powierzchni upraw. Producenci sa zainteresowani uzyskaniem dobrej jakości plonów. Wysoki procentowy udział zbóż w strukturze zasiewów wiąże się $\mathrm{z}$ koniecznością uprawy ich w monokulturze, czego konsekwencją jest duże nasilenie występowania szkodników, chorób i chwastów.

Celem badań było określenie wpływu występowania chorób grzybowych na jakość oraz wysokość plonu pszenicy w północno-wschodniej Polsce. Ponadto oceniano skuteczność zastosowanej ochrony chemicznej na ograniczenie chorób grzybowych w pszenicy ozimej.

\section{Materiały i metody / Materials and methods}

Badania prowadzone były w latach 2011-2012, w województwie podlaskim, na polach rolnika indywidualnego. Doświadczenie założono w uprawach pszenicy ozimej odmiany Bogatka, w układzie bloków losowanych, w czterech powtórzeniach. W doświadczeniu badano wpływ chorób grzybowych na plon. Wielkość poletek wynosiła $20 \mathrm{~m}^{2}(5 \mathrm{~m} \times 4 \mathrm{~m})$. Zabiegi uprawowe, nawożenie oraz zwalczanie chwastów prowadzono zgodnie $\mathrm{z}$ zaleceniami Intytutu Ochrony Roślin (Zalecenia 2010/2011, 2012/2013).

Zabiegi chemiczne wykonano przy użyciu poletkowego opryskiwacza plecakowego na sprężone powietrze, z zamontowanymi 4 rozpylaczami (fungicyd XR Tee Jet 110 $02 \mathrm{VP}$, herbicyd $11003 \mathrm{VP}$ ), przy wydatku cieczy 300 1/ha. Wykonano zabiegi: herbicydem Chwastox Turbo
$340 \mathrm{SL}(2,5$ 1/ha) w terminie A w fazie BBCH 21-23 rośliny uprawnej, fungicydem Duett Ultra $497 \mathrm{SC}$ $(0,6 \mathrm{l} / \mathrm{ha}) \mathrm{w}$ terminie $\mathrm{B} \mathrm{w}$ fazie $\mathrm{BBCH} 22-23$ oraz fungicydem Amistar $250 \mathrm{SC}(0,8 \mathrm{l} / \mathrm{ha}) \mathrm{w}$ terminie $\mathrm{C}$ w fazie BBCH 71-75 (tab. 1).

Ocenę występowania chorób grzybowych wykonano zbierając 25 roślin po przekątnej z każdego poletka. Stopień porażenia roślin oceniano $\mathrm{w}$ warunkach laboratoryjnych wizualnie określając \% powierzchni porażenia podstawy źdźbła, poszczególnych liści i kłosów na roślinach (tab. 2) z poletek traktowanych fungicydem i poletek kontrolnych. Wyniki przedstawiono w skali procentowej, gdzie $100 \%$ - oznacza całkowite porażenie, a $0 \%$ - brak wystapienia choroby.

W celu określenia wpływu występujących chorób na jakość zboża, z powierzchni $1 \mathrm{~m}^{2}$ każdego poletka zebrano kłosy i wymłócono młocarenką laboratoryjną LD 180 ST 4. Po zbiorze plon zważono i określono masę 1000 ziaren oraz zmierzono wilgotność i gęstość za pomocą wilgotnościomierza „Dramiński”. Straty plonu ziarna spowodowane przez choroby grzybowe ustalono porównując plon z obiektów chronionych i kontrolnych. Wyniki przedstawiono w tabelach 3. i 4.

\section{Wyniki i dyskusja / Results and discussion}

W ciągu całego okresu badań występowały: ostra plamistość oczkowa (Rhizoctonia cerealis), łamliwość źdźbła (Pseudocercosporella herpotrichoides), septorioza plew pszenicy (Stagonaspora nodorum), septoriozy liści pszenicy (Phaeosporia nodorum), brunatna plamistość liści (Pyrenophora tritici-repentis) i rdza brunatna (Puccinia recondita). Stwierdzono zróżnicowanie porażenia roślin w zależności od zastosowanej ochrony chemicznej (tab. 2). W przypadku porażenia przez wszystkie choroby występujące na I liściu oraz większości na II liściu, kłosie

i źdźble nie stwierdzono istotnej różnicy pomiędzy obiektem kontrolnym (brak ochrony chemicznej) a obiektem

Tabela 1. Zabiegi ochronne wykonane w uprawie pszenicy ozimej Table 1. The protective measures taken in winter wheat

\begin{tabular}{|c|c|c|c|c|c|}
\hline $\begin{array}{l}\text { Nr obiektu } \\
\text { No. of } \\
\text { treatment }\end{array}$ & $\begin{array}{l}\text { Obiekty doświadczenia } \\
\text { Variants of the experiment }\end{array}$ & $\begin{array}{c}\text { Substancja czynna (s.cz) } \\
\text { Active substance (a.s.) }\end{array}$ & $\begin{array}{c}\text { Zawartość } \\
\text { s.cz. } \\
\text { Content } \\
\text { a.s. }\end{array}$ & $\begin{array}{c}\text { Dawka } \\
\text { Dose } \\
{[\mathrm{kg}, \mathrm{l} / \mathrm{ha}]}\end{array}$ & $\begin{array}{l}\text { Termin } \\
\text { Date of } \\
\text { treatment }\end{array}$ \\
\hline 1 & $\begin{array}{l}\text { Kontrola } \\
\text { Untreated }\end{array}$ & - & - & - & - \\
\hline 2 & Chwastox Turbo 340 SL & $\begin{array}{l}\text { MCPA } \\
\text { dicamba }\end{array}$ & $\begin{array}{c}300 \mathrm{~g} / 1 \\
40 \mathrm{~g} / 1\end{array}$ & 2,5 & A \\
\hline \multirow{2}{*}{3} & Duett Ultra 497 SC & $\begin{array}{l}\text { tiophanate-methyl } \\
\text { epoxiconazole }\end{array}$ & $\begin{array}{l}310 \mathrm{~g} / 1 \\
187 \mathrm{~g} / 1\end{array}$ & 0,6 & B \\
\hline & Amistar $250 \mathrm{SC}$ & azoxystrobin & $250 \mathrm{~g} / 1$ & 0,8 & $\mathrm{C}$ \\
\hline \multirow{3}{*}{4} & Chwastox Turbo 340 SL & $\begin{array}{l}\text { MCPA } \\
\text { dicamba }\end{array}$ & $\begin{array}{c}300 \mathrm{~g} / 1 \\
40 \mathrm{~g} / 1\end{array}$ & 2,5 & A \\
\hline & Duett Ultra 497 SC & $\begin{array}{l}\text { tiophanate-methyl } \\
\text { epoxiconazole }\end{array}$ & $\begin{array}{l}310 \mathrm{~g} / 1 \\
187 \mathrm{~g} / 1\end{array}$ & 0,6 & B \\
\hline & Amistar $250 \mathrm{SC}$ & azoxystrobin & $250 \mathrm{~g} / 1$ & 0,8 & $\mathrm{C}$ \\
\hline
\end{tabular}

Termin - Treatment date: A - BBCH 21-23, B - BBCH 22-23, C - BBCH 71-75 
Tabela 2. Stopień porażenia roślin [\%]

Table 2. The degree of infestation of plants [\%]

\begin{tabular}{|c|c|c|c|c|c|c|c|c|c|c|c|c|}
\hline \multirow[b]{2}{*}{$\begin{array}{c}\text { Nr obiektu } \\
\text { No. of treatment }\end{array}$} & \multicolumn{3}{|c|}{$\begin{array}{l}\text { I liść } \\
\text { I leaf }\end{array}$} & \multicolumn{3}{|c|}{$\begin{array}{l}\text { II liść } \\
\text { II leaf }\end{array}$} & \multicolumn{3}{|c|}{$\begin{array}{l}\text { III liść } \\
\text { III leaf }\end{array}$} & \multicolumn{2}{|c|}{$\begin{array}{l}\text { Podstawa źdźbła } \\
\text { Stem blades }\end{array}$} & \multirow{2}{*}{ 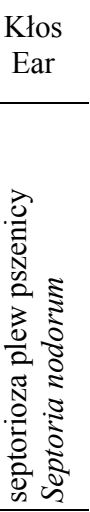 } \\
\hline & 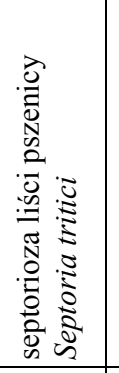 & 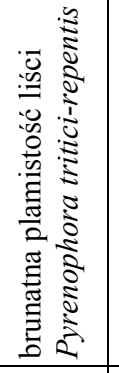 & 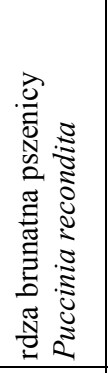 & 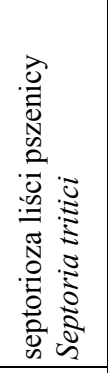 & 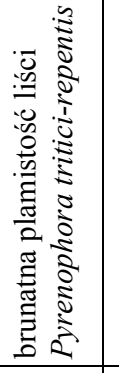 & 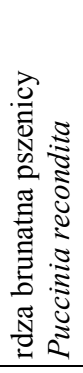 & 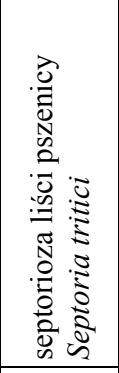 & 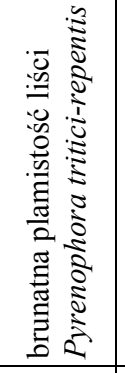 & 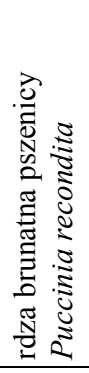 & 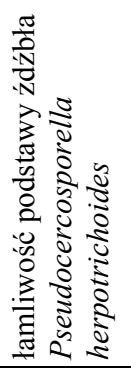 & 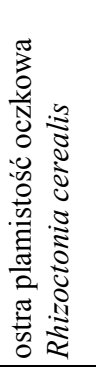 & \\
\hline $\mathrm{K}$ & $34 \mathrm{a}$ & $21,9 \mathrm{a}$ & $11,4 \mathrm{a}$ & 68,4 a & $14,2 \mathrm{a}$ & 7,8 & $100 \mathrm{a}$ & $100 \mathrm{a}$ & $96 \mathrm{a}$ & 16,8 & $4,7 \mathrm{a}$ & $1,3 \mathrm{a}$ \\
\hline 2 & $22,8 \mathrm{~b}$ & $10,5 \mathrm{ab}$ & $7,5 \mathrm{ab}$ & 64,6 a & $5,6 \mathrm{ab}$ & 6,2 & $90 \mathrm{a}$ & $59,2 \mathrm{ab}$ & $59 \mathrm{ab}$ & 14 & $1,9 \mathrm{ab}$ & $0,9 \mathrm{ab}$ \\
\hline 3 & $11,6 \mathrm{bc}$ & $2 b$ & $0,1 \mathrm{~b}$ & $38,3 \mathrm{~b}$ & $2,7 \mathrm{~b}$ & 0,1 & $77,7 \mathrm{~b}$ & $0 \mathrm{~b}$ & $0 \mathrm{~b}$ & 16,9 & $2 b$ & $0,1 \mathrm{~b}$ \\
\hline 4 & $6,6 \mathrm{c}$ & $1,4 \mathrm{~b}$ & $0 \mathrm{~b}$ & $26,2 \mathrm{~b}$ & $1,7 \mathrm{~b}$ & 0 & $42 \mathrm{~b}$ & $0,1 \mathrm{~b}$ & $0 \mathrm{~b}$ & 9,8 & $1,2 \mathrm{~b}$ & $0,5 \mathrm{~b}$ \\
\hline $\begin{array}{l}\operatorname{NIR}(0,05) \\
\operatorname{LSD}(0.05)\end{array}$ & 8,9 & 8,7 & 7 & 15,1 & 5,1 & r.n. & 31,6 & 38,6 & 38,3 & r.n. & 2,1 & 0,5 \\
\hline
\end{tabular}

I liść - liść flagowy - I leaf - flag leaf

$\mathrm{K}$ - poletka kontrolne bez zastosowanej ochrony - control plots without applied protection

Średnie oznaczone tymi samymi literami nie różnią się istotnie według testu Fishera $(\alpha=0,05)$

Means marked by the same letter are not statistically different according to Fisher's test $(\alpha=0.05)$

r.n. - różnica nieistotna - not significant difference

Tabela 3. Parametry plonu

Table 3. Yield parameters

\begin{tabular}{|c|c|c|c|c|c|c|c|c|c|c|c|c|}
\hline \multirow[t]{2}{*}{$\begin{array}{c}\text { Nr obiektu } \\
\text { No. of treatment }\end{array}$} & \multicolumn{3}{|c|}{$\begin{array}{c}\text { Gęstość próbki } \\
\text { Sample density } \\
{[\mathrm{kg} / \mathrm{hl}]}\end{array}$} & \multicolumn{3}{|c|}{$\begin{array}{c}\text { Masa } \\
\text { Weight } \\
{\left[\mathrm{kg} / \mathrm{m}^{2}\right]}\end{array}$} & \multicolumn{3}{|c|}{$\begin{array}{l}\text { Plon } \\
\text { Yield } \\
\text { [t/ha] }\end{array}$} & \multicolumn{3}{|c|}{$\begin{array}{c}\mathrm{MTZ}-\mathrm{TSW} \\
{[\mathrm{g}]}\end{array}$} \\
\hline & 2011 & 2012 & średnia & 2011 & 2012 & średnia & 2011 & 2012 & średnia & 2011 & 2012 & średnia \\
\hline K & 75,3 & 78,7 & $77,0 \mathrm{a}$ & $0,580 \mathrm{a}$ & 0,211 & 0,396 & $7,35 \mathrm{a}$ & 2,11 & 4,73 & $49,7 \mathrm{a}$ & 35,8 & 42,7 \\
\hline 2 & 72,8 & 78,8 & $75,8 \mathrm{~b}$ & $0,690 \mathrm{a}$ & 0,231 & 0,461 & $8,78 \mathrm{ab}$ & 2,31 & 5,55 & $47,3 \mathrm{~b}$ & 36,9 & 42,1 \\
\hline 3 & 75,1 & 78,1 & $76,6 \mathrm{a}$ & $0,720 \mathrm{~b}$ & 0,250 & 0,485 & $9,15 \mathrm{~b}$ & 2,50 & 5,83 & $50,2 \mathrm{a}$ & 37,0 & 43,6 \\
\hline 4 & 76,0 & 79,2 & $77,6 \mathrm{a}$ & $0,743 \mathrm{~b}$ & 0,349 & 0,546 & $9,57 \mathrm{c}$ & 3,39 & 6,50 & $51,3 \mathrm{a}$ & 38,4 & 44,9 \\
\hline $\begin{array}{l}\text { NIR }(0,05) \\
\operatorname{LSD}(0.05)\end{array}$ & r.n. & r.n. & 0,7 & 0,080 & 0,016 & r.n. & 0,99 & 0,11 & 0,11 & 1,5 & r.n. & 0,2 \\
\hline
\end{tabular}

$\mathrm{K}$ - poletka kontrolne bez zastosowanej ochrony - control plots without applied protection

Średnie oznaczone tymi samymi literami nie różnią się istotnie według testu Fishera $(\alpha=0,05)$

Means marked by the same letter are not statistically different according to Fisher's test $(\alpha=0.05)$

r.n. - różnica nieistotna - not significant difference

MTZ - TSW - masa tysiąca ziaren - thousand seed mass

na którym wykonano zabieg herbicydowy. Jednocześnie zaobserwowano brak istotnych różnic w stopniu porażenia brunatną plamistością liści, rdzą brunatną pszenicy i septoriozą plew pszenicy na wszystkich poletkach, na których zastosowano chemiczną ochronę przed chwastami i chorobami.

Stopień porażenia roślin pszenicy miał wpływ na masę plonu i masę tysiąca ziaren (tab. 3, 4). Na kombinacjach, gdzie zastosowano herbicyd Chwastox Turbo 340 SL zauważono zmniejszoną liczebność chwastów i stwierdzono mniejsze nasilenie chorób. Przyczyną tego mogło być obniżenie wilgotności na skutek zwalczenia chwastów, co nie sprzyjało rozwojowi patogenów na liściach (Narkiewicz-Jodko i wsp. 2005) w przeciwieństwie do sytuacji zaobserwowanej w badaniach Lemańczyka i Jaskulskiego (2006). Najmniejsze porażenie pszenicy ozimej zaobserwowano na poletkach, gdzie zastosowano pełną ochronę (Chwastox Turbo 340 SL, Duett Ultra 497 SC, Amistar $250 \mathrm{SC}$ ). W największym stopniu pszenica była porażona na poletkach kontrolnych, na których nie zastosowano żadnych zabiegów chemicznych. Występowanie chorób miało wpływ na plon ziarna $\mathrm{z}$ poszczególnych 
Tabela 4. Długość źdźbła i kłosa [cm]

Table 4. Blade length and ear $[\mathrm{cm}]$

\begin{tabular}{c|c|c|c|c|c|c}
\hline \multirow{2}{*}{$\begin{array}{c}\text { Nr obiektu } \\
\text { No. of treatment }\end{array}$} & \multicolumn{3}{|c|}{ Źdźbło - Stalk } & \multicolumn{4}{c}{ Kłos - Ear } \\
\cline { 2 - 8 } & 2011 & 2012 & $\begin{array}{c}\text { średnia } \\
\text { mean }\end{array}$ & 2011 & \multicolumn{2}{c}{$\begin{array}{c}2012 \\
\text { średnia } \\
\text { mean }\end{array}$} \\
\hline K & 71,7 & 127,9 & 99,8 & 8,4 & 4,3 & $6,3 \mathrm{a}$ \\
\hline 2 & 68,0 & 130,4 & 99,7 & 8,4 & 4,8 & $6,5 \mathrm{ab}$ \\
\hline 3 & 70,4 & 129,9 & 98,2 & 8,5 & 5,1 & $6,5 \mathrm{a}$ \\
\hline 4 & 68,5 & 136,3 & 99,7 & 8,5 & 5,9 & $6,5 \mathrm{~b}$ \\
\hline NIR (0,05) - LSD (0.05) & r.n. & r.n. & r.n. & r.n. & r.n. & 0,6 \\
\hline
\end{tabular}

$\mathrm{K}$ - poletka kontrolne bez zastosowanej ochrony - control plots without applied protection

Średnie oznaczone tymi samymi literami nie różnią się istotnie według testu Fishera $(\alpha=0,05)$

Means marked by the same letter are not statistically different according to Fisher's test $(\alpha=0.05)$

r.n. - różnica nieistotna - not significant difference

poletek (tab. 3). Najwyższy plon ziarna uzyskano w kombinacjach, w których stosowano fungicydy Duett Ultra 497 SC i Amistar 250 SC oraz herbicyd Chwastox Turbo $340 \mathrm{SL}$. W porównaniu z poletkami kontrolnymi był on aż o $28 \%$ wyższy. Najniższy plon zebrano $\mathrm{z}$ poletek, na których wykonano zabieg środkiem Chwastox Turbo 340 SL i na poletkach kontrolnych, na których nie stosowano żadnego środka (tab. 3, 4). Ponadto MTZ była o 5\% wyższa na poletkach, gdzie zastosowano pełną ochronę (herbicyd + fungicyd). Przyczyną obniżenia plonu było silne zachwaszczenie i występowanie chorób grzybowych.

\section{Wnioski / Conclusions}

1. Występowanie chorób grzybowych wpływa znacząco na obniżenie oraz jakość plonu.

2. Najskuteczniejszą ochronę pszenicy przed występowaniem chorób grzybowych uzyskano dzięki łącznemu zastosowaniu fungicydu $\mathrm{z}$ herbicydem.

\section{Literatura / References}

Lemańczyk G., Jaskulski D. 2006. Wpływ zwalczania chwastów i przedplonu na zdrowotność pszenicy ozimej i pszenżyta ozimego. [Effect of weed control and forecrop on health condition of wheat and winter triticale]. Prog Plant Prot./Post. Ochr. Roślin 46 (2): $149-152$.

Narkiewicz-Jodko M., Gil Z., Urban M. 2005. Porażenie podstawy źdźbła pszenicy ozimej przez Fusarium spp. - przyczyny i skutki. Acta Agrobot. 58 (2): 319-332.

Zalecenia Ochrony Roślin na lata 2010/2011. Cz. II, Rośliny Rolnicze. 2010. Inst. Ochr. Roślin, Poznań: 153-188.

Zalecenia Ochrony Roślin na lata 2012/2013. Cz. II, Rośliny Rolnicze. 2012. Inst. Ochr. Roślin, Poznań: 147-191. 